\title{
UNCERTAINTY, FLEXIBILITY AND OPERATIONAL PERFORMANCE OF COMPANIES: MODELLING FROM THE PERSPECTIVE OF MANAGERS
}

\author{
ADILSON ADERITO SILVA \\ Universidade Presbiteriana Mackenzie (UPM), São Paulo - SP, Brazil. \\ FERNANDO COELHO MARTINS FERREIRA \\ Fundação Getúlio Vargas (FGV-EAESP), São Paulo - SP, Brazil.
}

To cite this paper: Silva, A. A., \& Ferreira, F. C. M. (2017). Uncertainty, flexibility and operational performance of companies: modelling from the perspective of managers. Revista de Administração Mackenzie, 18(4), 11-38. doi 10.1590/1678-69712017/administracao.v18n4p11-38 


\section{ABSTRACT}

Purpose: The purpose of this study is to propose a model to estimate how uncertainty, flexibility, and operational performance are related. The assumption is that competition in the current business environment has been broadening consumers' options. These options have brought uncertainty to companies regarding the adoption of operational strategies, particularly to adjustment of flexibility to their competitive priorities.

Originality/value: The research designed a theoretical model that presents convergent, discriminant validity, and good reliability. Therefore, it is possible to estimate the perceived uncertainty, flexibility, and operational performance from a set of evaluated companies.

Design/methodology/approach: Data was collected out of managers and analysts from the financial, energy, and manufacturing sectors. The uncertainty was estimated by taking into account the state, the effect, and the choice of responses from changes in business environment. In addition, it was considered the flexibility and the performance within the operational indicators.

Findings: The results reveal moderate managers' ability to predict the state of the environment and its effects on their organization's activities. Also they show that uncertainty does not influence the operational performance when mediated by flexibility. Thus, in a moderate environmental stability, flexibility can be adopted to mitigate the effects of uncertainty on operational performance.

\section{KEYWORDS}

Uncertainty. Operational performance. Flexibility. Business environment. Proactive strategy. 


\section{INTRODUCTION}

Conducting studies about perceptions of uncertainty and organizations' operational performance in the context of the external environment has proved to be a challenging endeavour due to the complex nature of these two theoretical constructs. Uncertainty is defined as a situation in which the probability of events is unknown (Knight, 1921) and it can be characterized by insufficient knowledge of the external environment of organizations due to its dynamism and complexity, which are identified as dimensions that affect the uncertainty perception of managers (Duncan, 1972; Lawrence \& Lorsch, 1967).

Definitions of uncertainty have always been present in strategic planning models. Milliken (1987, p. 133) considered a "psychological state of doubt as to the meaning of the events of current events or what events might occur in the future". In the same vein, Bradac (2001, p. 464) defined it as "a cognitive state of the individual, resulting from the evaluation of the number of alternatives available to predict future behavior or alternatives available to explain a past behavior". More recently, DiFonzo (2002) described uncertainty as a result of unforeseen circumstances that cannot be properly understood.

We observe in these definitions a consensus among authors that uncertainty is a perceptive phenomenon, so the ability of managers to access, process and anticipate future events, based on the information provided, becomes an essential factor in choosing operating strategies to meet the demands of a competitive market, obtain higher returns and ensure the survival of the business. In this context, the characterization of the correct strategic decisions is reflected in successful management performance measures.

Organizational performance is recognized as one of the most important constructs in the polls concerning strategy (Combs, Crook, \& Shook, 2005). The review conducted by the authors of 374 articles published in the Strategic Management Journal (SMJ) in the period from 1980 to 2004 revealed the presence of 56 performance indicators, most of which are financial. Elsewhere, in the operations area, White (1996) found 125 operational performance indicators associated with the 5 competitive priorities enshrined in operations, namely flexibility, reliability, quality, speed and cost.

The plethora of indicators reveals the importance of business performance; however, opinions diverge when trying to determine the best measure for evaluating performance in organizations (Glick, Washburn, \& 
Muller, 2005). Financial measures have predominated as companies' guidance for strategic decisions, despite some criticism, since a system of accounting measures does not meet needs that extend beyond cost analysis, such as the benchmarking of operations in terms of strategic alignment, especially when managers are dealing with a dynamic environment, turbulence and uncertainty (Neely, Richards, Mills, Platts, \& Bourne, 1997).

In the recent past, studies have investigated the performance of organizations in uncertain environments, focusing on planning and the delegation of authority (Thompson, 1967); differentiation and specialization structures (Galbraith, 1974; Lawrence \& Lorsch, 1967); environmental scanning systems (Yasai-Ardekani \& Nystrom, 1996); and the informal processes of decision making (Fredrickson, 1986; Mintzberg, Raisinghani \& Théorêt, 1976). While some have found an inverse relationship between uncertainty and organizations' performance (Swamidass \& Newell, 1987), others have found a moderating effect of uncertainty on the adoption of flexible budget models and performance on purchases (Haka \& Krishnan, 2005). However, in these studies, the analysis of operational performance is based partly on financial indicators, which can skew the results against the cost of flexibility.

This study is guided by the use of non-financial measures in assessing the operational performance. The aim here is to propose a model that allows the estimation of the relationship between uncertainty, flexibility and businesses' operational performance and, therefore, answers the following research question: what is the influence of uncertainty perceived by managers and flexibility on companies' operational performance? To this end, the following objectives were established: 1 . to estimate the uncertainty perceived by managers about the state of the external environment; the effects of the changes and the decisions made; and the choice of possible answers to environmental changes; 2 . to estimate organizations' operational performance based on the indicators categorized by White (1996); and 3. to estimate and test the relationship between the perceived uncertainty of the environment and the operational performance of companies, as well as the effects of flexibility on this relationship.

The work is divided into sections: the theoretical studies on uncertainty and operational performance will be presented; the methodological procedures will be discussed along with the indicators and procedures used in the data analysis; the results will be presented and analysed; and, lastly, the final considerations will be made, which will expose the main contributions and suggestions of the study. 


\section{THEORETICAL BACKGROUND}

This section will discuss the uncertainty perceived by managers considering the complexity and dynamism of organizations' external environment, as well as companies' operational performance and their relationship with uncertainty and flexibility.

\subsection{PERCEIVED ENVIRONMENTAL UNCERTAINTY}

In recent decades, researchers have sought to understand the causes of uncertainty and develop indicators that can test its influence in various situations experienced by managers when dealing with external organizations. The work by Knight (1921) was one of the precursors of these studies and defined a situation of uncertainty in which there is no valid basis for the calculation of probabilities of the event, thus distinguishing the concept of risk. Barnard (1938) argued that organizations' survival depends on the managers' ability to maintain equilibrium with the external environment by adjusting the internal process needs imposed by the environment, since he already considered environmental instability to be a factor that generates uncertainty.

From this perspective, Lawrence and Lorsch (1967) sought to combine the information about the sales environment, production and research and development to study the uncertainty perceived by managers in 20 British companies. The authors concluded that the genesis of uncertainty is the lack of clarity of information, the general uncertainty of causal relationships and the amplitude of time for feedback on results.

Based upon these seminal studies, Duncan (1972) related uncertainty to the dynamism and complexity of the factors that make up organizations' external environment. For the author, the degree of complexity and environmental dynamism varies according to managers' perceptions; however, the more specific and measurable characteristics of the environment-volatility projections, the number of competitors, the degree of competition and the similarity of the products in the sector - would cause similar uncertainty perceptions. Like Lawrence and Lorsch (1967), the author argued that uncertainty originates from the absence of information on the environmental factors associated with the decision-making process as well as the lack of knowledge about the results of a decision and from the absence of managers' ability to predict the effects of a given factor on the company performance. 
The exposure of these sources of uncertainty suggests that uncertainty is not an objective feature of the environment, but rather that the individual who perceives a psychological trait individually and as such should be evaluated subjectively (Downey \& Slocum, 1975; Weick, 1969). Thus, it is necessary to explore in greater depth the characteristics and environmental attributes that affect the perception of uncertainty, since, according to Milliken (1987), changes in the external environment expose the level of managers' rationality in decision making, at a time when they can experience three types of uncertainty: 1. the uncertainty effect or managers' inability to predict the effects of changes in the external environment on business operations, that is, the inability to predict the impact of a possible future state of the environment; 2 . the state of uncertainty related to possible environmental conditions, namely uncertainty about the changes that may occur in the factors or components of the external environment, such as concentration, volatility, complexity and heterogeneity, which make the environment more or less predictable; and 3. response uncertainty associated with the managers' difficulty in choosing the best response from the available options as well as in predicting the responses of competitors to a particular strategy that the company will perform.

The uncertainty definitions in the studies undertaken by Barnard (1938), Duncan (1972), Lawrence and Lorsch (1967) and Milliken (1987) indicate the existence of a common belief: it is impossible for officers to obtain knowledge about organizations' external environment and such ignorance creates uncertainty. In light of this argument and understanding that this phenomenon is an individual and affordable psychological trait from the perception of managers, it was decided in this study to adopt a subjective measurement of uncertainty, operationalized as a reflective multidimensional construct from the three types of uncertainty proposed by Milliken (1987).

\subsection{OPERATIONAL PERFORMANCE}

Organizational performance is widely recognized as an important construct in the research strategy (Combs et al., 2005). Indeed, the emphasis on business performance is presented as one of the elements that distinguishes this field from other areas of organizational studies (Glick et al., 2005).

From the perspective of Venkatraman and Ramanujam (1986), financial performance and operational performance are the main determinants 
of the effectiveness of a company. While the financial sector involves indicators such as sales growth, profitability and earnings per share, among others, the operational area is related to measures such as market share, the introduction of new products, product quality and value added in manufacturing, among others. However, the way in which performance is measured varies widely.

A study by Combs et al. (2005), involving the analysis of 374 articles published in the Strategic Management Journal (SMJ) in the period 1980-2004, revealed 56 different performance indicators, 33 of which were related to financial performance and the rest to operational performance. In the opinion of the authors, this plurality of indicators suggests the multidimensionality of this construct, a fact that does not prevent researchers from representing it with a single indicator (Glick et al., 2005; Murphy, Trailer, \& Hill, 1996).

The historical predominance of the use of financial measures to measure companies' performance can be explained by the fact that outside groups exert great influence on such measures as well, and the measurement systems of the internal performance of a company have also tended to be financial and usually to have a focus on costs. However, the use of cost accounting systems that include measures of efficiency and variance to guide a company towards the correct strategic decisions has been questioned. According to Skinner (1974, p. 33):

A major cause of companies getting into trouble with manufacturing is the tendency for many managements to accept simplistic notions in evaluating performance of their manufacturing facilities... the general tendency in many companies is to evaluate manufacturing primarily on the basis of cost and efficiency. There are many more criteria to judge performance.

Such a statement suggests that a major problem with traditional performance measurement systems is the adoption of a narrow, onedimensional focus. One response to this situation has arisen through the new approaches to cost accounting, such as activity-based costing (ABC). Other authors, however, have argued that even an improved cost accounting system does not solve the problem of the need for measures that extend beyond the cost to assess the performance of operations properly in terms of alignment with the company's competitive strategy (Neely et al., 1997). This problem, according to Kaplan and Norton (1996), can be overcome by adopting a "balanced" set of measures to address the financial, internal 
business, customer and innovation and learning areas in an organization, through the recognized model of the balanced scorecard.

Despite the agreement on the need to use non-financial measures, there seems to be little convergence regarding which measures to use. Part of the reason is each company's need to use measures that are relevant to its own situation. On the other hand, the selection of some common basic performance measures would be valuable, both to avoid undue proliferation of measures and to ensure that important variables are measured correctly. The latter reason applies particularly to academic research, which has more recently collected data to evaluate operational performance (Neely et al., 1997).

Through a literature review, Swink and Way (1995) found that competitive priorities form an essential decision-making variable for managers and researchers in operations, whose strategic focus is the development of certain operational skills to leverage the position of the firm in the market.

In recent decades, the relative convergence framework emerged regarding the content of the operational strategy. Most researchers have come to see the strategy of operations from the viewpoint of the relative weight of the cost, quality, flexibility, reliability and speed in operations. Although some conceptual studies have suggested the ability to innovate and service additional priorities, empirical research and strategic theories have emphasized the classical performance objectives (Boyer \& McDermott, 1999; Boyer \& Pagell, 2000). Notwithstanding the great interest in the topic of operating strategy, White (1996) pointed out that in both the business world and the academic world, the consensus on the structuring of operational performance measures remains apart from the need for convergence to improve business performance systems.

Through an in-depth literature review, White (1996) identified 125 operational performance indicators and organized them into 5 performance objectives considered relevant to operations for the methodology proposed in this study (cost, quality, speed, reliability, and flexibility). Among the dozens of indicators found for each performance objective, most of them are subjective in nature and are intended to capture managers' perception about the performance of their company in relation to its main competitors. In this study, the operational performance will also be measured subjectively as a multidimensional construct based on the indicators proposed by White (1996), in which flexibility is considered to be a mediating variable in the relationship between the operational performance and the uncertainty perceived by managers. 


\subsection{UNCERTAINTY, FLEXIBILITY AND OPERATIONAL PERFORMANCE}

Based on the studies by Milliken (1987) and White (1996) and other papers presented in the previous section, a model is proposed to explore the relationship between the uncertainty perceived by managers, the flexibility and the operational performance of companies.

The analysis of the external environment and performance has been considered a decisive factor in drawing up the strategy of a business (Swamidass \& Newell, 1987). These authors reinforced the idea included in the study (Milliken, 1987) about uncertainty, because the external environment is recognized as a source of changes, which require information relevant to decision making. However, access to such information does not occur symmetrically between managers (Williamson, 1985), either due to market imperfections or due to the limited capacity of managers to interpret them. As a result, changes in the external environment expose the managers' difficulty in interpreting and selecting the alternatives and in predicting the effects of environmental changes on the organization (Duncan, 1972).

Therefore, the ability to predict changes in the environment (state uncertainty), the inability to predict the effects of these changes on the organization (effect of uncertainty) and the difficulty in choosing alternatives to such changes (response uncertainty) reflect the level of uncertainty perceived by managers. This argument outlines the operationalization of uncertainty perceived by managers as a multidimensional construct reflected by the state of uncertainty, the effect of uncertainty and response uncertainty.

In the study by Swamidass and Newell (1987) and the review by Khatri and D'Netto (1997), the authors pointed out that uncertainty is revealed as a negative influence variable on changes in the financial performance of organizations. In the present study, this relationship will also be tested in the first hypothesis; however, performance will be estimated using nonfinancial measures.

H1: The perception of uncertainty has an impact on the operational performance estimated by the managers in the companies studied.

The role of managers in the decision-making process is guided by the search for alternatives to deal with uncertainties (Thompson, 1967). Flexibility in this process is potentially relevant because the response to environmental changes will be maintained or replaced in organizations as a 
result of actions coordinated and aligned with the strategic policy adopted (Swamidass \& Newell, 1987). In this way, flexibility is generally addressed in the literature in two strategic areas: in the form of a defensive strategy, related to an organization's ability to adapt and respond to environmental changes with as little possible time and cost (Das, 1995; Gupta \& Goyal, 1989; Sánchez \& Pérez, 2005; Swamidass \& Newell, 1987; Upton, 2011); and in the form of a proactive strategy to generate initiatives to meet the market needs and exceed the competitors' possibilities (Gerwin, 1993; Vickery, Calantone, \& Droge, 1999).

From the proactive perspective, flexibility is associated with the reintegration of the market or the ability to change when it ceases to be attractive to consumers. Therefore, flexibility can be considered a specific strategic asset of great importance to enhancing the competitive position of organizations, a critical factor that can affect their profitability and longterm survival (Aranda, 2003; Dreyer \& Gronhaug, 2004) and, consequently, their performance.

H2: Flexibility has an impact on the operational performance estimated by the managers in the companies studied.

Global competition has produced more choice for consumers and increased the uncertainty in organizations. The study by Pagell and Krause (1999) in the real estate sector and the study by Vickery et al. (1999) in the manufacturing sector found no significant effects of uncertainty relating to the flexibility of operations. Thus, uncertainty has been the basic assumption used in the literature on operations to support investments and increase operational flexibility (Pagell \& Krause, 2003; Suarey, Cusumano, \& Fine, 1991).

In the study by Swamidass and Newell (1987) in the machinery and equipment sector and that by Sánchez and Pérez (2005) in the automotive industry, the authors concluded that in uncertain environments, increased flexibility results in improved performance, but in more predictable environments, the high cost of flexibility accounts for economic losses, which result in lower financial performance. This result was also confirmed by Merschamann and Thonemann (2009), in whose study less flexible organizations performed better in more predictable environments, and under high levels of uncertainty, greater flexibility results in better performance. Therefore, the results indicate that the uncertainty level perceived by managers impact the extent of flexibility to be adopted in organizations (Anand \& Ward, 2004). This relationship will be tested in the third hypothesis: 
H3: The perception of uncertainty in the external environment has an impact on the operational flexibility level estimated by managers in the companies surveyed.

Similarly, the magnitude and the kind of strategic flexibility to be used also depend on the level of uncertainty in the environment perceived by managers (Ketokivi, 2006). The author found that in more predictable environments, there is a greater tendency to adopt flexibility as a proactive strategy, and in less predictable environments, such a choice fell into the defensive category. So, adjustments to balance the flexibility costs in accordance with the environment conditions are needed to gather gains and performance improvements (Anand \& Ward, 2004). Therefore, the impact of strategic flexibility on operational performance will depend on the level of uncertainty that is perceived by managers, thus:

H4: The operational performance appointed by managers in the studied companies is influenced by the combined effect of flexibility and uncertainty.

Considering the results presented, the study proposes the theoretical model illustrated in Flowchart 1, with the relationships and assumptions made in the theoretical framework. The next section will present the methodological procedures adopted in the study.

\section{(Flowchart 1)}

THEORETICAL MODEL REFERENCE

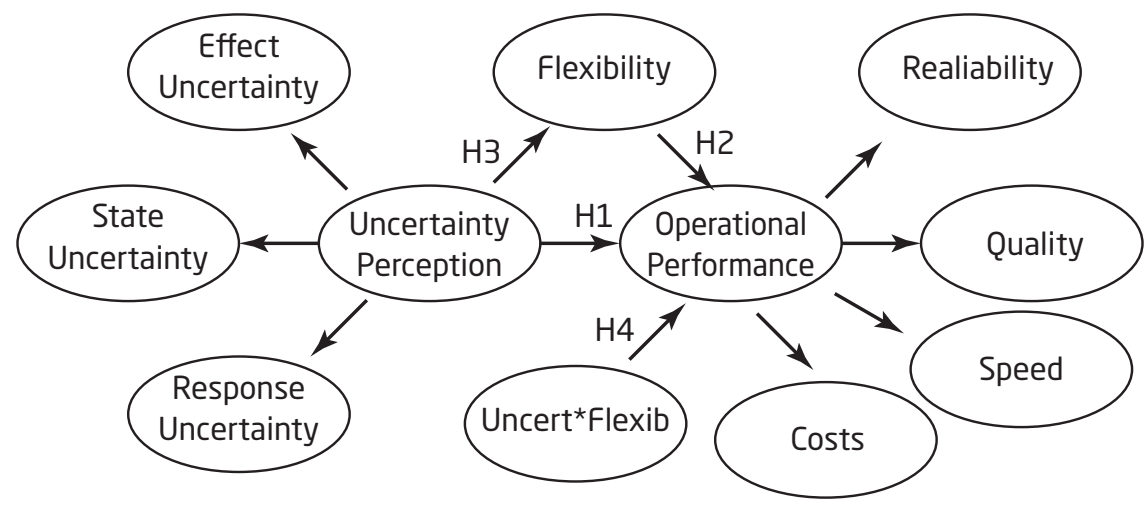

Source: Elaborated by the authors. 


\section{METHODOLOGY}

Considering the nature of the relationships proposed in the reference model and the form of data collection, the quantitative method was adopted for the analysis of data collected through a questionnaire with 21 indicators on a Likert scale, contained in Table 1 and Table 2.

The data processing will be conducted in stages. First, the descriptive statistics technique will be used to characterize the profile of the companies and survey respondents and check outliers and missing values. Second, the data will be submitted to structural equation modelling by the partial least square method (PLS-SEM), which allows the simultaneous examination of a series of dependency relationships without the classic requirements of the maximum likelihood method and the sample size and multivariate normality (Lohmöller, 1989). It also allows the evaluation of the reliability of the indicators, revealing how strongly intercorrelated the present reliability rates are. Rates greater than or equal to 0.70 represent convergent validity and discriminant validity (Chin, 1998; Hair, Black, Babin, Anderson, \& Tatham, 2009).

\section{(Table 1)}

\section{ASSERTIONS USED TO ESTIMATE UNCERTAINTY}

\begin{tabular}{|c|c|}
\hline Dimensions & Assertions (Likert scale from 1 = strongly disagree to 5 = strongly agree) \\
\hline Effect uncertainty & $\begin{array}{l}\text { Effect } 1 \text { - I am enabled to predict the effects of changes in the external } \\
\text { environment on the organization's activities. }\left({ }^{\star}\right) \\
\text { Effect } 2 \text { - The effects of changes in the external environment on the } \\
\text { organization's activities are quickly provided by the company. }\left({ }^{*}\right) \\
\text { Effect } 3 \text { - I am convinced in my predictions about the effects of the } \\
\text { changes of the external environment on the organization's activities before } \\
\text { a decision is taken. }\left(^{\star}\right)\end{array}$ \\
\hline State uncertainty & $\begin{array}{l}\text { State } 1 \text { - I make use of the information needed to predict how the elements } \\
\text { of the organization's external environment will change in the future. }\left(^{\star}\right) \\
\text { State } 2 \text { - I have the ability to predict which states of the external } \\
\text { environment may affect decision making in the organization. }\left(^{\star}\right) \\
\text { State } 3 \text { - It is difficult to monitor trends to market our products. } \\
\text { State } 4 \text { - The strategic moves of our competitors have become more } \\
\left.\text { predictable in the last year. }{ }^{\star}\right) \\
\text { State } 5 \text { - It is difficult to predict the strategic actions of our customers. }\end{array}$ \\
\hline
\end{tabular}

(continue) 


\section{(Table 1)}

\section{ASSERTIONS USED TO ESTIMATE UNCERTAINTY}

\begin{tabular}{l|l}
\hline Dimensions & \begin{tabular}{l} 
Assertions (Likert scale from 1 = strongly disagree to 5 = strongly agree) \\
\hline Response 1 - I am convinced that all the alternatives available to the company \\
are considered to respond to changes in the external environment. ${ }^{*}$ ) \\
Response 2 - Considering the various alternatives available to respond \\
to changes in the external environment, it is difficult to decide which one \\
will be best for the organization in the long run. Response 3 - You cannot \\
accurately evaluate each of the alternatives available to the company to \\
respond to environmental changes, because there are many factors that \\
influence them. \\
Response 4 - The number of alternatives available to the company to \\
respond to market changes complicates the assessment of each of them.
\end{tabular} \\
\hline
\end{tabular}

Source: Adapted from Milliken, 1987.

${ }^{(*)}$ Assertions prepared using a reverse scale; assertions in italics were deleted from the analysis to present low factor loadings.

\begin{tabular}{|c|c|}
\hline \multicolumn{2}{|r|}{ ASSERTIONS USED TO ESTIMATE PERFORMANCE } \\
\hline $\begin{array}{l}\text { Performance } \\
\text { objectives }\end{array}$ & Assertions \\
\hline Flexibility & $\begin{array}{l}\text { Flexib } 1 \text { - The ability to use my product portfolio to meet customer demands in } \\
\text { relation to competition. }\left(^{*}\right) \\
\text { Flexib } 2 \text { - The ability to speed up its process to meet the real needs of } \\
\text { customers regarding the competition. }\left(^{\star}\right)\end{array}$ \\
\hline Reliability & $\begin{array}{l}\text { Reliab - The percentage of transactions that need to be made due to } \\
\text { operational errors compared with the competition. }\left(^{\star}\right)\end{array}$ \\
\hline Quality & $\begin{array}{l}\text { Quality } 1 \text { - The image of my brand perceived by the customer in relation to the } \\
\text { brand's main competitor. }\left(^{*}\right) \\
\text { Quality } 2 \text { - The relationship between the amount of claims and the number of } \\
\text { transactions/sales in relation to the competition. }\left({ }^{\star}\right) \\
\text { Quality } 3 \text { - The percentage of casualties in the customer base compared with } \\
\text { the same percentage of my biggest competitor. }\left(^{\star}\right)\end{array}$ \\
\hline
\end{tabular}

(continue) 


\section{(Table 2)}

\section{ASSERTIONS USED TO ESTIMATE PERFORMANCE}

\begin{tabular}{l|l}
\hline $\begin{array}{c}\text { Performance } \\
\text { objectives }\end{array}$ & Assertions \\
\hline Speed & $\begin{array}{l}\text { Speed }- \text { The speed of service from the customer contact until the conclusion of } \\
\text { the service compared with the competition. }\left(^{*}\right)\end{array}$ \\
\hline Cost & $\begin{array}{l}\text { Cost } 1 \text { - The company's operating costs to total costs when compared with the } \\
\text { biggest competitor. }\left(^{*}\right) \\
\text { Cost } 2 \text { - The productivity of employees who work directly with the end } \\
\text { customer, regarding the productivity of the same level as my biggest } \\
\text { competitor of employees. }\left({ }^{*}\right)\end{array}$ \\
\hline
\end{tabular}

Source: Adapted from White, 1996.

${ }^{*}$ ) indicates the low intensity (1) at (5) high.

Nevertheless, the possibility of the simultaneous examination of predictive relations with PLS-SEM will be adopted in the processing of data following the step-by-step approach to evaluate the possible effects of interaction with each new relationship introduced into the model. In the first stage, the influence of uncertainty on operational performance will be tested. To this end, the factor loadings, average variance extracted and reliability of these two constructs will be estimated. In the second stage, the construct flexibility will be introduced into the model with the aim of testing its influence on operational performance and the influence of uncertainty on flexibility. In the third stage, the interaction term will be introduced to evaluate the combined effect of uncertainty and flexibility in operational performance. In this last stage, the psychometric properties of the model proposed in the study will be assessed.

Convergent validity is usually examined using the average variance extracted (AVE). This measure includes the portion of variance of the indicators that a latent construct captures relative to the total amount of variance. Therefore, a higher value (0.50) indicates that over $50 \%$ of the variance of the indicators is explained by the construct (Chin, 1998; Fornell $\&$ Larcker, 1981). The examination of the discriminant validity will be undertaken through the comparison of the AVE roots and the correlations between the constructs.

In PLS-SEM, the sample size suggested by the process (Chin, 1998) responding to assertions is 5 or 5 to 10 times the number of relationships 
presented by the construct with the largest number of influence relationships. In this study, uncertainty presented 3 relationships, so the required size of the sample is 30 respondents.

The parameters for the analysis of factor loadings of the measurement model and the structural coefficients were determined post hoc with the software G Power 3.0, taking into account the sample size of 50 respondents, the statistical significance of $5 \%$ and the statistical power of 0.80 . The size of the resulting effect of factor loadings was 0.34 and 0.20 for the structural coefficients. The charges will be evaluated using the "t" student generated in bootstrapping with 500 repetitions.

The moderating effect of flexibility in the relationship between the perception of uncertainty and the operational performance will be tested to examine the significance of the interaction term and according to the $\mathrm{f}^{2}$ effect size calculated following the recommendations (Chin, Marcolin, \& Newsted, 1996) for the reason $\mathrm{f}^{2}=\left[\mathrm{R}^{2}\right.$ (interact with) $-\mathrm{R}^{2}$ (no interaction) $]$ $/ \mathrm{R}^{2}$ (no interaction). Securities $\mathrm{f}^{2} \leq 0.02$ indicate weak influence; $0.02 \leq$ $\mathrm{f}^{2} \leq 0.15$ moderate influence; and $\mathrm{f}^{2} \geq 0.35$ strong influence (Chin, 1998; Cohen, 1988).

\section{RESULTS}

The data collection in the research culminated in a non-probabilistic sample of 50 respondents, mostly from operational management. The descriptive analysis of the data revealed that $58 \%$ of the respondents worked in the financial sector; $24 \%$ in the energy sector; $14 \%$ in manufacturing; and $2 \%$ in the health care industry; $2 \%$ did not answer. Regarding their position, $58 \%$ work as managers; $28 \%$ as analysts; and $8 \%$ on operational tasks; $6 \%$ did not answer. The manufacturing sector had the lowest level of turnover among those surveyed, with an average time of 7.3 years in operation, followed by the financial sector with an average of 6.6 years.

The Model 1 processing with PLS-SEM using the path weighting scheme algorithm with uncertainty indicators and an operational performance standard (Mean: 0; Variance: 1) revealed that the statements "State 4", "State 5", "Response 1", "Speed 2" and "Speed 3" correlated with loads below the reference level $\lambda=0.30$ and were suppressed. After these changes, a second processing of Model 1 (restructured) was performed, the results of which are illustrated in Flowchart 2. 


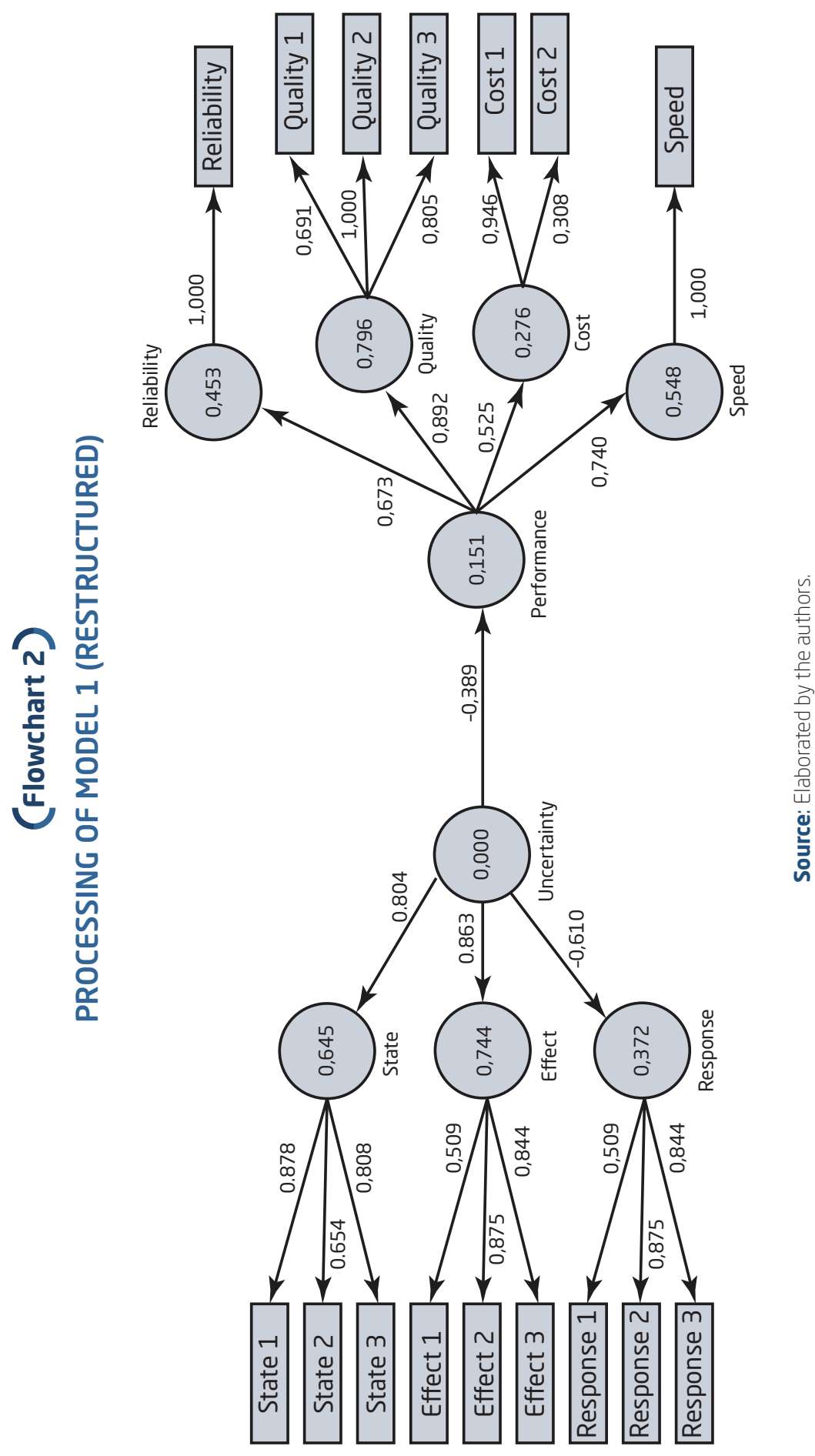


The composite reliability (CR) and average variance extracted (AVE) indexes were calculated manually and the resulting values of these measures for the uncertainty construct were (0.587 and 0.788) and (0.527 and 0.839 ) for the performance construct. Therefore, the reliability indicators meet the levels suggested in the PLS-SEM literature.

The managers perceived a moderate uncertainty level $\left({ }^{-} x=3.06\right.$; $s d=0.79)$ and had a negative and significant impact on operational performance of organizations studied at the 5\% level $(\gamma=-0.389, \mathrm{t}=$ 2.397; p-value $=0.020$ ). This result is similar those presented in the study by Swamidass and Newell (1987) and the review by Khatri and D'Netto (1997) that used financial indicators to assess operational performance of organizations.

As shown in Flowchart 3, at the $5 \%$ level, there is a significant influence of uncertainty on flexibility $(\gamma=-0.290 ; t=2.596 ; \mathrm{p}$-value $=0.012)$ and flexibility on operational performance $(\gamma=0.708 ; \mathrm{t}=16.777$; $\mathrm{p}$-value $=$ 0.000). Also apparent is a significant increase in the variance of operational performance caused by the introduction of flexibility into the model, from $15.1 \%$ to $60.4 \%$, as well as a decrease in the direct negative effect of uncertainty on operational performance, from $(\gamma=-0.389)$ to $(\gamma=-0.175$; $\mathrm{t}=3.002$; p-value $=0.004$ )

This can be explained by the moderate level of uncertainty perceived by managers as was also observed by Merschamann and Thonemann (2009), less flexible organizations performed better in more predictable environments due the high costs of flexibility, although this becomes an incentive to adopt proactive strategies in organizations in order to improve operational performance (Ketokivi, 2006).

The results reinforce the role of managers in the search for alternatives to deal with uncertainty, among which flexibility stands out as a strategic response to improve the competitive position and profitability of organizations (Aranda, 2003; Dreyer \& Gronhaug, 2004; Swamidass \& Newell, 1987; Thompson, 1967). Therefore, the results support the assertion that flexibility is a major strategic resource to enhance the operational performance of organizations.

The significant reduction of the direct effect of uncertainty as a result of introducing flexibility into the model leads to the importance and extent of the interaction effect of these two constructs in operational performance. To capture the moderating effect of flexibility in the relationship between uncertainty and operational performance, Model 3 (the theoretical model proposed in the study) was processed. 


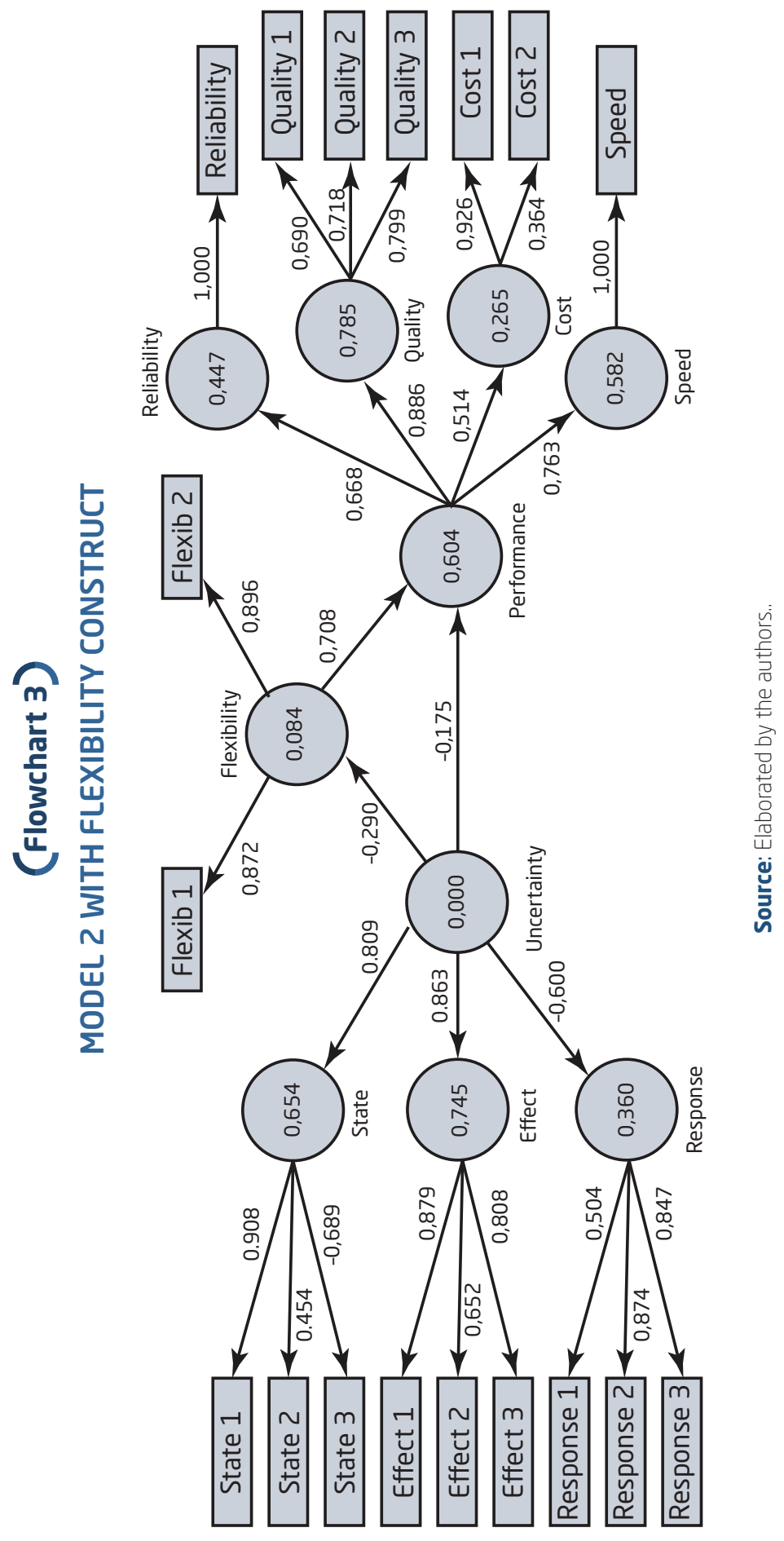


As illustrated in Flowchart 4, the results indicate that the interaction effect of uncertainty and flexibility on performance $(\gamma=0.276 ; t=2.099$; p-value $=0.041)$ was significant at the $5 \%$ level and the size of the resulting effect $\left(f^{2}=0.038\right)$ was moderate (Chin, 1998; Cohen, 1988). It appears further that the combined effect of these two constructs mitigated the effect of uncertainty on performance. Although the effect of flexibility $(\gamma=0.647 ; \mathrm{t}$ $=7.577$; p-value $=0.000$ ) has also decreased, the influence on performance remained significant at the $5 \%$ level and the relationships proposed in the theoretical model explains $67.4 \%$ of the variance of the perceived operational performance of companies studied.

Therefore, the results reinforce the arguments (Anand \& Ward, 2004; Chang, Lin, \& Sheu, 2002) regarding the need to combine flexibility and uncertainty to balance the costs of flexibility and encourage better operational performance of organizations. In addition to testing the assumptions made in the study, it is necessary to evaluate the psychometric properties of the reference model used in the last processing.

The factor loadings of the reflective constructs in Flowchart 4 show values above the threshold stipulated in the post hoc test. This is the first indication that the statements converge in their respective constructs. Thus, to assess whether the statements are appropriate to measure the proposed constructs, the indicators of composite reliability and average variance explained, processed with PLS-SEM, are reproduced in Chart 1 . The results indicate that the values of composite reliability and AVE were above the reference levels of 0.70 and 0.50, as recommended (Chin, 1998; Fornell \& Larcker, 1981; Hair et al., 2009). Chart 1 shows that the mean scores of the uncertainty constructs revealed that managers have moderate/high levels of skill to predict the state of the external environment and its effects on the organization's activities, as well as a moderate/lower level of difficulty in assessing and choosing the alternative response to environmental changes.

To facilitate the analysis of the discriminant validity of the model, the roots of the average variance explained (AVE) were organized on the main diagonal of the correlation matrix in Chart 2. The magnitudes of the correlations between the constructs are smaller than those of the correlations between the statements and their respective constructs, so the model meets the requirement for discriminant validity. 


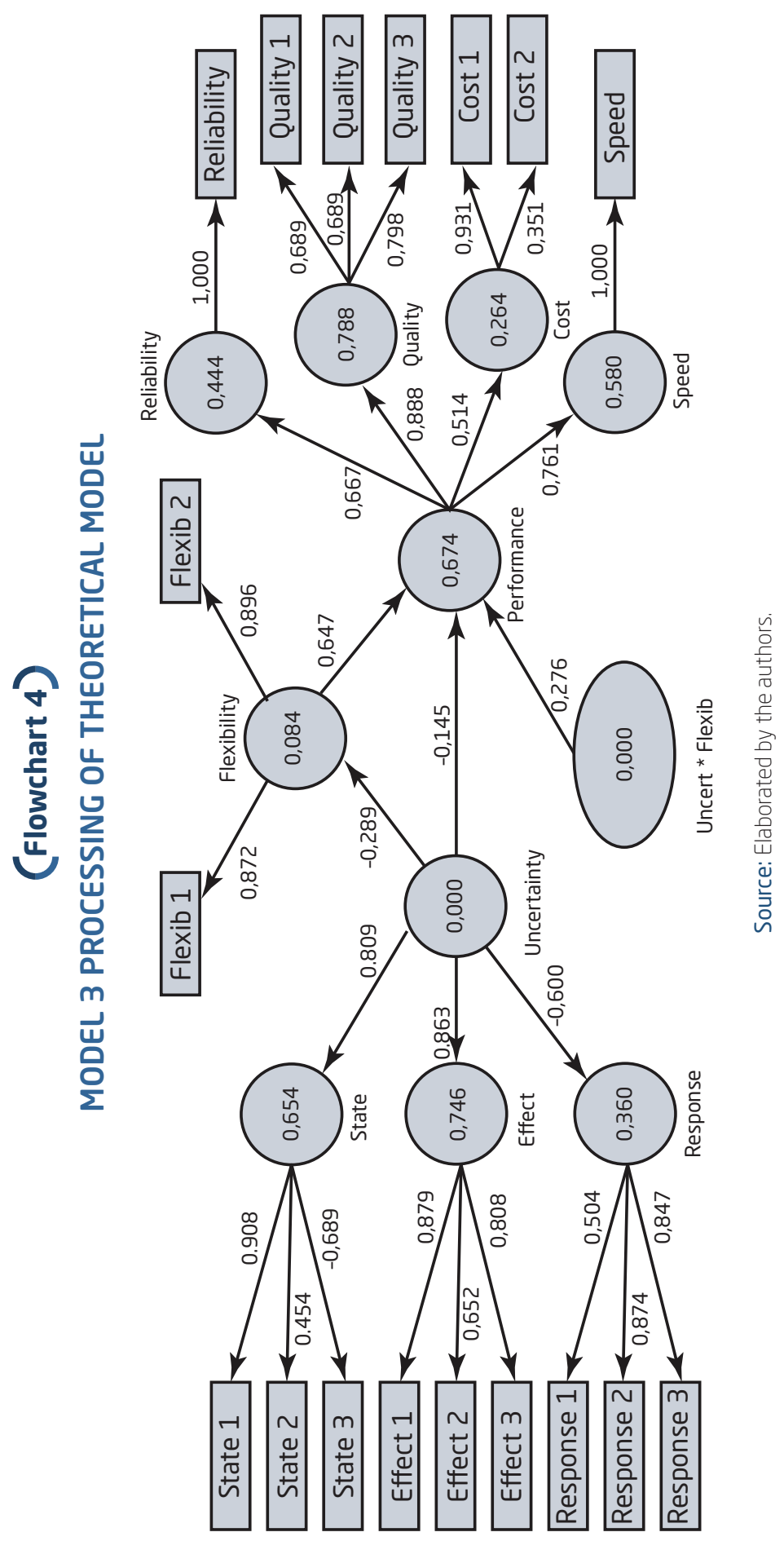




\section{(Chart 1)}

PLS-SEM SUMMARY OF THE PROCESSING OF ANSWERS TO ENVIRONMENTAL CHANGES

\begin{tabular}{lccccccc}
\hline & AVE & C.R. $^{\left({ }^{(a)}\right.}$ & $\mathrm{R}^{2}$ & Communalities & Redundancy & Mean & SD \\
\hline Flexibility & 0.782 & 0.877 & 0.083 & 0.782 & 0.065 & 3.29 & 0.83 \\
\hline Effects & 0.617 & 0.826 & 0.741 & 0.617 & 0.448 & 3.17 & 0.78 \\
\hline State & 0.502 & 0.738 & 0.652 & 0.502 & 0.293 & 3.04 & 0.65 \\
\hline Responses & 0.579 & 0.798 & 0.367 & 0.579 & 0.205 & 2.96 & 0.79 \\
\hline Uncertainty & 0.587 & 0.807 & n.a. ${ }^{(b)}$ & 0.587 & $0 . a$ & 3.06 & 0.79 \\
\hline Performance & 0.519 & 0.821 & 0.692 & 0.607 & 0.229 & 3.22 & 0.62 \\
\hline
\end{tabular}

(a) composite reliability; (b) does not apply; SD - standard deviation.

Source: Elaborated by the authors.

\section{(Chart 2)}

MATRIX OF CORRELATIONS BETWEEN LATENT VARIABLES

\begin{tabular}{lllll} 
& Effects & State & Response & Flexibility \\
\hline Effects & $\mathbf{0 . 7 8 5}$ & & & \\
\hline State & 0.554 & $\mathbf{0 . 7 0 8}$ & & \\
\hline Response & 0.298 & 0.267 & $\mathbf{0 . 7 6 1}$ & \\
\hline Flexibility & 0.247 & 0.311 & 0.062 & $\mathbf{0 . 8 8 4}$
\end{tabular}

Source: Elaborated by the authors.

This result, together with the significance of the factor loadings and the values obtained for the index of composite reliability and AVE, supports the assertion that the model also has convergent validity. Therefore, the indicators used are shown to be consistent and appropriate to measure these constructs. Chart 3, below, presents a summary of the results from the PLS-SEM. 


\section{(chart 3)}

SUMMARY OF THE RESULTS OBTAINED FROM PLS-SEM

\begin{tabular}{lccccc}
\hline Processing & Hypotheses & Coefficients & "t" Student & p-value & Results \\
\hline Model 1-Restruc & H1: Uncertainty $\rightarrow$ Perform & -0.389 & 2.397 & 0.020 & Supported \\
\hline \multirow{2}{*}{ Model 2 } & Hz: Flexib $\rightarrow$ Perform & 0.708 & 16.777 & 0.000 & Supported \\
\cline { 2 - 6 } & H3: Uncertainty $\rightarrow$ Flexib & -0.289 & 2.596 & 0.012 & Supported \\
\hline Model 3 & H4: Uncertainty * Flexib & 0.276 & 2.099 & 0.041 & Supported \\
\hline
\end{tabular}

Source: Elaborated by the authors.

\section{CONCLUSIONS}

This study was conducted to propose a model that allows the estimation of the relationship between uncertainty, flexibility and companies' operational performance. To this end, it designed a theoretical model of reference presenting convergent validity, discriminant validity and good reliability, making it possible to estimate and test the relationships between these constructs. From the processing of data using the PLS-SEM method, it was possible to estimate the perceived uncertainty in the companies surveyed from the perspective of managers in relation to the state of the external environment, the effects of changes and decisions taken and alternative responses to the changes in the external environment. The data processing also allowed the estimation of the operational performance of the companies studied from the indicators categorized according to performance objectives by White (1996). Therefore, the specific goals outlined in the study were fully achieved.

The results of the study indicated that managers showed moderate levels of ability to predict the state of the external environment and its effects on their organization's activities; however, they faced moderate difficulty in evaluating alternatives and choosing responses to environmental changes. Such perceptions became intertwined, forming a moderate perception of uncertainty of the managers in the companies surveyed.

The assumptions made in the study were supported by the results of the research; uncertainty has significantly influenced the operational performance and the level of flexibility adopted in the companies surveyed. 
It was also possible to observe the moderating effect of flexibility in the relationship between uncertainty and performance, that is, the results indicated that the level of flexibility acted as a factor mitigating the effects of uncertainty on performance.

From these results, it could be inferred that with the moderate level of uncertainty, managers can gather greater predictability about the external environment, so the difficulties involved in interpreting and selecting alternative responses to environmental changes are minor. Therefore, under these conditions, flexibility can be used as a proactive strategy to improve operational performance. This situation was evidenced by the significant interaction between uncertainty and flexibility in operational performance.

The study contributes to the advancement of the research on the subject in two ways. The first concerns the operationalization of the constructs of uncertainty and operational performance, which will allow other relationships not covered in this study to be tested in future studies. The second is marked by the expansion of research using non-financial measures for assessing operational performance, which is generally measured by financial indices that do not reflect the alignment of operations and operational performance strategies adopted in a company.

Despite the contributions, the study is not without limitations, among which is the number of respondents who agreed to answer the survey, perhaps due to the scarcity of time that these managers have to participate in scholarly research. The second limitation is guided by the sample type adopted in the study, which does not allow the generalization of the results and restricts the validity of the results of the companies surveyed. The third is marked by the distinctive nature of the activities undertaken by the companies, since the sectors of activity are diverse. As a suggestion for future studies, it is recommended that the research is replicated with a greater number of respondents chosen randomly from a single sector of activities.

\section{REFERENCES}

Anand, G., \& Ward, P. T. (2004). Fit, flexibility and performance in manufacturing: coping with dynamic environments. POMS, 13(4), 369-385. doi 10.1111/j.1937-5956.2004.tb00224.x. 
Aranda, D. A. (2003). Service operations strategy, flexibility and performance in engineering consulting firms. International Journal of Operations $\mathcal{E}$ Production Management, 23(11), 1401-1421. doi 10.1108/01443570310501907.

Barnard, C. I. (1938). The Functions of the Executive. Ott, J. S. (Ed.). Harvard University Press: Cambridge, MA, p. 376.

Boyer, K. K., \& Mcdermott, C. (1999). Strategic consensus in operations strategy. Journal of Operations Management, 17(3), 289-305. doi 10.1016/ S0272-6963(98)00042-4.

Boyer, K. K., \& Pagell, M. (2000). Measurement issues in empirical research: improving measures of operations strategy and advanced manufacturing technology. Journal of Operations Management, 18(3), 361-374. doi 10.1016/ S0272-6963(99)00029-7.

Bradac, J. J. (2001). Theory comparison: uncertainty reduction, problematic integration, uncertainty management, and other curious constructs. Journal of Communication, 51 (3), 456-476. doi 10.1111/j.1460-2466.2001.tb02891.x. Chang, S.-C., Lin, N.-P., \& Sh.eu, C. (2002). Aligning manufacturing flexibility with environmental uncertainty: evidence from high-technology component manufacturers in Taiwan. International Journal of Production Research, 40(18), 4765-4780. doi 10.1080/00207540210157196.

Chin, W. W. (1998). The partial least squares approach to structural equation modeling. In Marcoulides, G. A. (Ed.). Modern Methods for Business Research. Mahwah, NJ: Lawrence Erlbaum Associates, 295-336. doi 10.1016/j. aap.2008.12.010.

Chin, W. W., Marcolin, B. L., \& Newsted, P. R. (1996). A partial least squares latent variable modeling approach for measuring interaction effects: results from a Monte Carlo simulation study and voice mail emotion/adoption study. In Proceedings of the Seventeenth International Conference on Information Systems, Cleveland, Ohio, 14, 20-41.

Cohen, J. (1988). Statistical Power Analysis for the Social Sciences (2nd ed.). Hillsdale, NJ: Lawrence Erlbaum Associates.

Combs, J. G., Crook, T. R., \& Shook, C. L. (2005). The dimensionality of organizational performance and its implications for strategic management research. Research Methodology in Strategy and Management, 2(5), 259-286. doi 10.1016/S1479-8387(05)02011-4.

Das, T. K. (1995). Managing strategic flexibility: key effective performance. Journal of General Management, 20(3), 60-76. doi 10.1177/030630709502000305. 
DiFonzo, N. (2002). Corporate rumor activity, belief and accuracy. Public Relations Review, 28(1), 1-19. doi 10.1016/S0363-8111(02)00107-8.

Downey, K. H., \& Slocum, J. W. (1975). Uncertainty: measures, research, and sources of variation. Academy of Management Journal, 18(3), 562-578. doi $10.2307 / 255685$.

Dreyer, B., \& Gronhaug, K. (2004). Uncertainty, flexibility, and sustained competitive advantage. Journal of Business Research, 57(5), 484-494. doi 10.1016/S0148-2963(02)00315-6.

Duncan, R. B. (1972). Characteristics of organizational environments and perceived environmental uncertainty. Administrative Science Quarterly, 17(3), 313-327. doi 10.2307/2392145.

Fornell, C., \& Larcker, D. F. (1981). Evaluating structural equation models with unobservable variables and measurement error. Journal of Marketing Research, 18(1), 39-50. doi 10.2307/3151312.

Fredrickson, J. W. (1986). The strategic decision process and organizational structure. Academy of Management Review, 11(2), 280-297. doi 10.5465/ AMR.1986.4283101.

Galbraith, J. R. (1974). Organizational design: an information processing view. Interfaces, 4(3), 28-36. doi 10.1287/inte.4.3.28.

Gerloff, E. A. (1991). Three components of perceived environmental uncertainty: an exploratory analysis of the effects of aggregation. Journal of Management, 17(4), 749-768. doi 10.1177/014920639101700408.

Gerwin, D. (1993). Manufacturing flexibility: a strategic perspective. Management Science, 39(4), 395-410. doi 10.1287/mnsc.39.4.395.

Glick, W. H., Washburn, N. T. \& Muller, C. C. (2005). The myth of firm performance. In Annual Meeting of the American Academy of Management, Academy of Management, Honolulu, 1-28.

Grinyer, P. H., McKiernan, P., Yasai-Ardekani, M. \& Wiley, J. (1988). Market, organizational and managerial correlates of economic performance in engineering industry: the U.K. electrical industry. Strategic Management Journal, 9(4), 297-318. doi 10.1002/smj.4250090402.

Gupta, Y. P., \& Goyal, S. (1989). Flexibility of manufacturing systems: concepts and measurements. European Journal of Operational Research, 43(2), 119-135.

Hair, J. F., Black, W. C., Babin, B. J., Anderson, R. E., \& Tatham, R. L. (2009). Análise multivariada de dados. In Hair, J. F., Black, W. C., Babin, B. J., Anderson, R. E. and Tatham, R. L. (Eds.). Porto Alegre: Bookman, p. 688. 
Haka, S., \& Krishnan, R. (2005). Budget type and performance - the moderating effect of uncertainty. Australian Accounting Review, 15(35), 3-13. DOI10.1111/j.1835-2561.2005.tb00247.x.

Kaplan, R., \& Norton, D. (1996). Balanced Scorecard; Strategy into Action, Boston, MA: Harvard Business School Press. p. 329.

Ketokivi, M. (2006). Elaborating the contingency theory of organizations: the case of manufacturing flexibility strategies. Production and Operations Management, 15(2), 215-228. doi 10.1111/j.1937-5956.2006.tb00241.x.

Khatri, N., \& D'Netto, B. (1997). Perceived uncertainty and performance: the causal direction. Journal of Applied Management Studies, 6(2), 219-233.

Knight, F. (1921). Risk, Uncertainty and Profit. In Marx, H. S. (Ed.). Boston, MA: Houghton Miffin.

Lawrence, P. R., \& Lorsch, J. W. (1967). Differentiation and integration in complex organizations. Administrative Science Quarterly, 12(1), 1-47. doi $10.2307 / 2391211$.

Lohmöller, J. (1989). Latent Variable Path Modeling with Partial Least Squares.

Heidelberg: Physica-Verlag.

Merschamann, U., \& Thonemann, U. W. (2009). Supply chain flexibility, uncertainty, and firm performance: an empirical analysis of German manufacturing firms. International Journal of Production Economics, 130(1), 43-53. doi 10.1016/j.ijpe.2010.10.013.

Milliken, F. J. (1987). Three types of perceived uncertainty about the environment: state, effect, and response uncertainty. Academy of Management Review, 12(1), 133-143. doi 10.2307/257999.

Mintzberg, H., Raisinghani, D., \& Théorêt, A. (1976). The structure of 'unstructured' decision processes. Administrative Science Quarterly, 21 (2), 246-275. doi 10.2307/2392045.

Murphy, G. B., Trailer, J. W., \& Hill, R. C. (1996). Measuring performance in entrepreneurship research. Journal of Business Research, 36(1), 15-23. doi 10.1016/0148-2963(95)00159-X.

Neely, A., Richards, H., Mills, J., Platts, K., \& Bourne, M. (1997). Designing performance measures: a structured approach. International Journal of Operations \& Production Management, 17(11), 1131-1152. doi 10.1108/01443579710177888.

Pagell, M., \& Krause, D. R. (1999). A multiple-method study of environmental uncertainty and manufacturing flexibility. Journal of Operations Management, 17(3), 307-325. doi 10.1016/S0272-6963(98)00049-7. 
Pagell, M., \& Krause, D. R. (2003). Re-examining the relationship between operational flexibility and environmental uncertainty. Best Conference Paper, Academy of Management.

Sánchez, A. M., \& Pérez, M. P. (2005). Supply chain flexibility and firm performance: a conceptual model and empirical study in the automotive industry. International Journal of Operations \& Production Management, 25 (7), 681-700. doi 10.1108/01443570510605090.

Skinner, W. (1974). The decline, fall, and renewal of manufacturing. Harvard Business Review, 47(3), 138-145.

Suarey, F., Cusumano, M. A., \& Fine, C. (1991). Flexibility and Performance: $a$ Literature Critique and Strategic Framework. School, S. (Ed.), MIT, Massachusetts. Swamidass, P. M., \& Newell, W. T. (1987). Manufacturing strategy, environmental uncertainty and performance: a path analytic model. Management Science, 33(4), 509-524. doi 10.1287/mnsc.33.4.509.

Swink, M., \& Way, M. H. (1995). Manufacturing strategy: propositions, current research, renewed directions. International Journal of Operations \& Production Management, 15(7), 4-26. doi 10.1108/01443579510090381. Thompson, J. D. (1967). Organizations in Action. New York: McGraw Hill. Upton, D. M. (1997). Process range in manufacturing: an empirical study of flexibility. Management Science, 43(8), 1079-1092. doi 10.1287/ mnsc.43.8.1079.

Venkatraman, N., \& Ramanujam, V. (1986). Measurement of business performance in strategy research: a comparison of approaches. Academy of Management Review, 11(4), 801-814. doi 10.2307/258398.

Vickery, S. N., Calantone, R., \& Droge, C. (1999). Supply chain flexibility: an empirical study. Journal of Supply Chain Management, 35(3), 16-24. doi 10.1111/j.1745-493X.1999.tb00058.x.

Waddock, S. A. \& Isabela, L. A. (1989). Strategy, beliefs about the environment, and performance in a banking simulation. Journal of Management, 15(4), 617632. doi 10.1177/014920638901500410.

Weick, K. E. (1969). The Social Psychology of Organizing. Reading, MA: Addison-Wesley.

White, G. P. (1996). A survey and taxonomy of strategy-related performance measures for manufacturing. International Journal of Operations \& Production Management, 16(3), 42-61. doi 10.1108/01443579610110486.

Williamson, O. (1985). The Economic Institutions of Capitalism. New York: Free Press. 
Yasai-Ardekani, M., \& Nystrom, P. C. (1996). Designs for environmental scanning systems: tests of a contingency theory. Management Science, 42(2), 187-204. doi 10.1287/mnsc.42.2.187.

\section{ABOUT THE AUTHORS}

\section{ADILSON ADERITO SILVA}

PhD in Business Administration from the Department of Business Administration, Universidade Presbiteriana Mackenzie (UPM).

Director at the Center for Social and Applied Sciences,

Universidade Presbiteriana Mackenzie (UPM).

Rua da Consolação, 930, Consolação - São Paulo - SP - Brasil - CEP 01302-907

E-mail: asilva@mackenzie.br

\section{FERNANDO COELHO MARTINS FERREIRA}

$\mathrm{PhD}$ in Business Administration,

Fundação Getúlio Vargas (FGV-EAESP).

Professor at the Department of Industrial Production and Operations (POI),

Fundação Getúlio Vargas (FGV-EAESP).

Rua Itapeva, 474, $8^{\circ}$ andar, POI, Bela Vista, São Paulo - SP - Brasil - CEP 01332-000

E-mail: fernando.coelho@fgv.br 